\title{
THE MICRO-DETERMINATION OF RESIDUAL MOISTURE IN FREEZE-DRIED BIOLOGICAL MATERIALS
}

\author{
By P. R. W. BAKER \\ Chemical Division, The Wellcome Research Laboratories, Beckenham, Kent
}

(With Plate 13 and 2 Figures in the Text)

The residual moisture content of freeze-dried biological materials such as vaccines is generally thought to be one of the factors determining their stability, yet, in spite of its importance, very few attempts have been made to determine it on a micro-scale, or to compare the various methods in current use; namely, ovendrying, the Karl Fischer method, and the vapour-pressure method.

Some years ago a method was sought for routine moisture determinations on yellow-fever vaccine and distemper vaccine, prepared from suspensions of chick embryo by freeze-drying. Each ampoule of yellow-fever vaccine would contain about $10 \mathrm{mg}$. of sample, and the moisture content was believed to be less than $1 \%$; i.e. there would be less than $0 \cdot 1 \mathrm{mg}$. of water present. The distemper vaccine samples would be somewhat larger (30-40 mg.). There was the added complication that the samples were extremely hygroscopic.

This paper describes the method finally adopted for routine purposes, and also comparative results obtained by other methods.

It is perhaps convenient at this point to give a brief review of the methods mentioned above, with particular reference to their limitations.

Oven-drying. For the purpose of this review, the term oven-drying will be taken to include all methods in which a loss in weight is measured, whether at elevated temperatures or not.

According to Flosdorf (1949), the standard American method, and the only one approved by the National Institutes of Health, is to dry $1 \mathrm{~g}$. of the sample to constant weight in a vacuum over phosphorus pentoxide, at room temperature, although he also states that a temperature of $50^{\circ} \mathrm{C}$. will give equally good results in a shorter time.

The method can never be absolute, since it only measures 'loss in weight'. Moreover, it is always possible, with biological materials, that at low drying temperatures the moisture will be incompletely released or that the time for complete release will be inconveniently long. On the other hand, the use of elevated temperatures may lead to decomposition of the sample. Flosdorf \& Webster (1937) found that $50^{\circ} \mathrm{C}$. is the maximum temperature at which serum can be dried without decomposition. Gardiner \& Farmiloe (1954), dealing with cane molasses, dried for $50 \mathrm{hr}$. at $70^{\circ} \mathrm{C}$. in a vacuum, and from the 'loss plus decomposition' curve obtained, extrapolated back to get the 'true loss'. Makower \& Myers (1943), dealing with dried foodstuffs, showed that results obtained by drying at $70^{\circ} \mathrm{C}$. in a vacuum could vary very greatly with the particle size of the sample, and with 
the duration of drying. Bennett and Hudson (1954), dealing with malt, suggested that enzyme activity, leading to hydrolysis of the starch or protein, may be responsible for inconsistent results. Riddick, Toops, Wiemann \& Cundiff (1954) found that dextran does not lose all its moisture on vacuum drying at $110^{\circ} \mathrm{C}$. Variations in pressure, from $5 \mathrm{~mm}$. to $0.05 \mathrm{~mm}$., had no apparent effect.

Several workers have applied the technique of 'reversible drying'. If the weight of the sample after drying and resorption of water is the same as the initial weight, it is assumed that no decomposition has taken place. This technique is obviously applicable only to hygroscopic substances initially in equilibrium with the atmosphere.

The Karl Fischer method. This method (Fischer, 1935) can be applied to substances which are not thermally stable, and has been used by several workers in this, and related, fields. It suffers from the defects that, as the reaction is not stoichiometric and the reagent is somewhat unstable, calibration with samples of known water content is required, and that several substances other than water may react with the reagent, leading to high results. Schroeder \& Nair (1948) found evidence for side-reactions between the reagent and a protein hydrolysate. If excess reagent was allowed to stand in contact with the sample for periods up to $4 \mathrm{hr}$., the results increased with time, and if varying amounts of reagent were allowed to stand in contact with the sample for $4 \mathrm{hr}$., the results increased with the amount of excess reagent present. By the nature of the reaction, it is necessary to work under completely anhydrous conditions, and consequently the method is not generally used when quantities of water of less than $1 \mathrm{mg}$. have to be determined.

Levy, Murtaugh \& Rosenblatt (1945) have described a Karl Fischer method for the determination of moisture in penicillin, and claimed a precision of $20-100 \mu \mathrm{g}$. for quantities of water of $1 \cdot 6-50 \mathrm{mg}$. Hutton, Hilmoe \& Roberts (1951) applied their procedure to samples of freeze-dried Brucella abortus, but reported 'the determination of less than $0.5 \%$ moisture in these samples, whose dry weight was about $35 \mathrm{mg}$., would require the determination of $250 \mu \mathrm{g}$. or less of water. Errors at this moisture level were so great that the results of determinations were meaningless'.

Sobel (1953) has recently described a technique whereby he determines very small amounts of water $(0 \cdot 1-0.5 \mathrm{mg}$.) in freeze-dried proteinaceous material. $\mathrm{He}$ makes a very dilute Fischer reagent, $10 \mathrm{ml}$. of which are mixed with the sample. The reduction in colour of the solution is measured with a spectrophotometer, and the amount of water read off from a standard curve relating the amount of water to the absorbance of the solution. He gives, however, no details regarding the maintenance of anhydrous conditions, beyond saying that 'the reaction is carried out in a dry box, or under ordinary conditions on a day with low humidity'. He implies that the results are high because of side reaction, as he further states 'non-aqueous reactants may be determined on a heat-dried sample'. By this technique he would presumably also tend to cancel out errors due to contamination by atmospheric moisture.

The vapour-pressure method. A vapour-pressure method has recently been developed in the research laboratories of Messrs W. Edwards and Company 
(London) Ltd., based on the earlier work of Makower \& Myers (1943) and Vincent $\&$ Simons (1940). In this method, a description of which has been given by Beckett (1954), the ampoule is opened inside an evacuated apparatus, and the moisture released from the sample condensed in a $U$-tube immersed in a $\mathrm{CO}_{2}$-alcohol bath. The increase in pressure in the system obtained by removal of the freezing bath is measured on a manometer, which is calibrated directly in terms of water. If carried out at room temperature, one determination takes several hours, but if the sample is heated to $50^{\circ} \mathrm{C}$., the time of determination is comparable to that for the method proposed in the present paper.

Comparative studies. Levy et al.(1945) compared the Fischer method with vacuum drying over phosphorus pentoxide, presumably at room temperature, for freezedried penicillin, and found that the vacuum drying method gave slightly higher results, which they attributed to moisture uptake during transfer from the ampoule to the weighing bottle.

McComb (1948) found that the Fischer method and oven-drying gave the same results for several proteinaceous materials, except for casein and peanut kernel, which gave lower results by the Fischer method.

On the other hand, Schroeder \& Nair (1948) found the Fischer method to give generally higher results than oven-drying, for dried foodstuffs, although their results for a protein hydrolysate were the same by both methods.

Sager (1952) found, for dried plasma containing glucose, that the Karl Fischer method gave higher results than vacuum drying over phosphorus pentoxide, but lower results than a method of distillation with xylene, based on the Dean and Stark principle (Thomann \& Kaelin, 1938).

As far as the present author is aware, no other relevant comparative results have been reported.

\section{METHOD}

In this laboratory, equipped for organic micro-analysis, it is a routine procedure to determine the moisture content of organic compounds by determining the loss in weight of a 5-10 mg. sample on drying in a vacuum at an elevated temperature (usually 80 or $100^{\circ}$ C.), and it seemed that such a method, embodying a technique with which we were already familiar, would prove satisfactory for the present purpose.

Several experiments were carried out, in which the samples were weighed into small glass weighing bottles, which were dried in a small vacuum oven, or platinum boats, weighed inside a 'boathouse' (Pregl, 1945) and dried in a Pregl microdesiccator. It was found, however, that the results were not sufficiently accurate, due probably to the inherent errors in weighing small glass vessels. The use of metal foil cups as weighing vessels led to greatly increased accuracy and reproducibility.

\section{(a) Apparatus}

Cups. Aluminium foil, 0.0006 in. thick, is cut into $1.5 \mathrm{in}$. squares and pressed round the flame-polished end of a $0.5 \mathrm{in}$. glass rod, to give cups approximately 0.5 in. diameter and $0.5 \mathrm{in}$. tall, which are dried at $100^{\circ} \mathrm{C}$. before use. 
JOURNAL OF HYGIENE, VOL. 53, NO. 4

PLATE 13

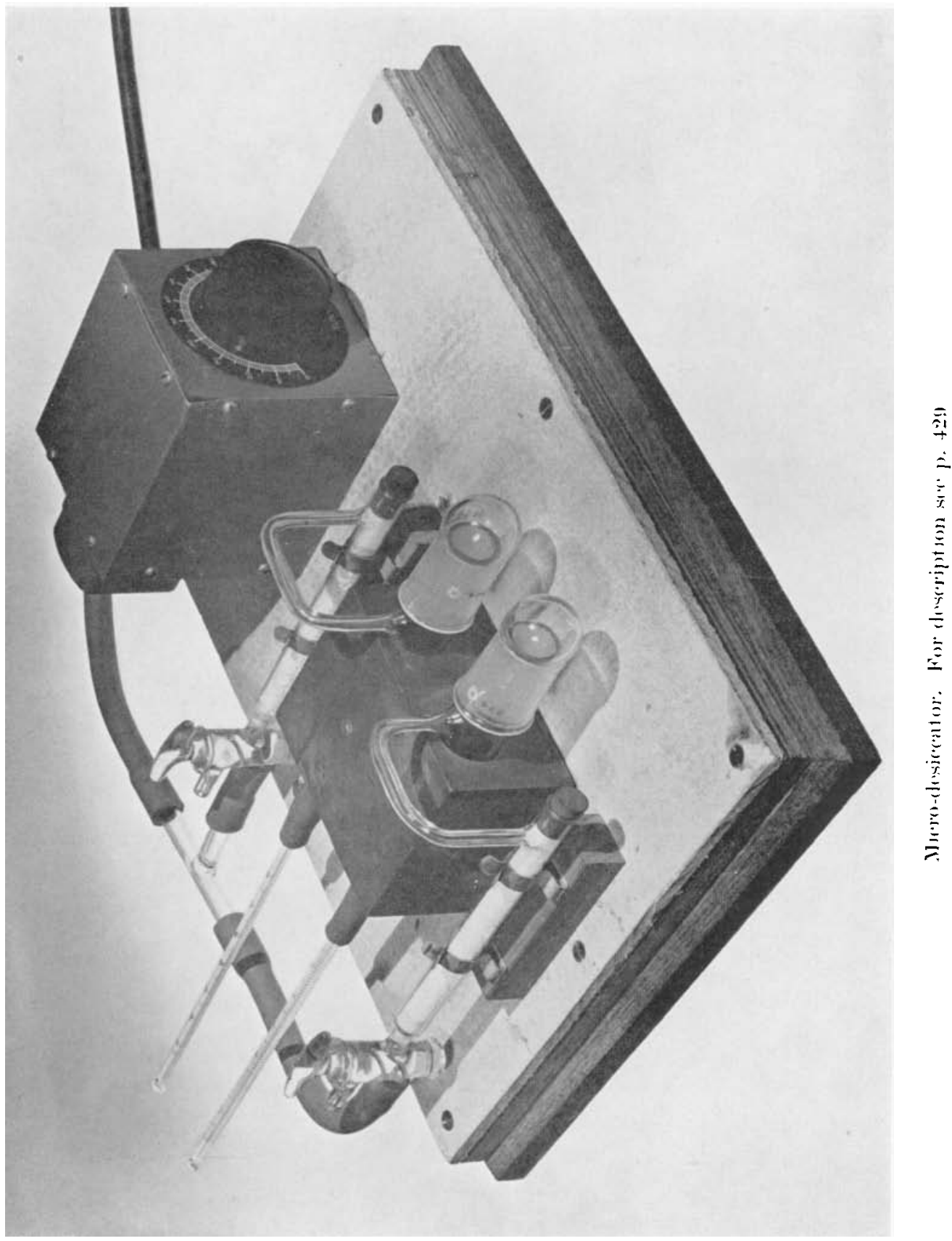


Micro-desiccator. This, shown in Pl. 13, consists of a copper block, $4 \times 3 \times 2$ in., to the bottom of which is clamped a 75-watt Henly 'Solon' element, controlled by a 'Sunvic' Energy Regulator, type TYB.

The block is drilled with two holes to take the drying tubes. Each of these tubes is fitted with a thermometer, through a rubber tubing sleeve-joint, and is connected to a two-way tap, through a drying tube filled with anhydrous magnesium perchlorate. The lower limb of the two-way tap is connected to the vacuum pump and the upper limb is left open for admission of air. The single drying tube thus serves to absorb moisture from the sample, and also to dry the incoming air after the determination.

\section{(b) Procedure}

Weigh a cup on the micro-balance (using, for convenience, a second cup as a counterpoise). Open the ampoule containing the sample, and simultaneously start a stop-watch (or note the time by a watch with a second hand). As quickly as possible, transfer the sample to the weighed cup; pinch the top of the cup lightly together with forceps, brush the outside to remove any adhering sample and replace the cup on the balance pan. As soon as possible (normally $1-1 \frac{1}{2} \mathrm{~min}$. after opening the ampoule), note the weight, and the time. Leave the cup on the balance pan, and note the weight after a further equal time interval. The difference between the two weights, subtracted from the first, will give the weight at 'zero time', if it is assumed that the increase in weight is linear during the first few minutes of exposure.

Transfer the cup to the micro-desiccator and dry at $50^{\circ} \mathrm{C}$. under vacuum $(c .0 .1 \mathrm{~mm} . \mathrm{Hg}$ ) for $45 \mathrm{~min}$. At the end of this time turn the two-way tap to admit air to the desiccator. A sudden inrush of air may be avoided by holding a filter paper over the inlet. Remove the cup, tightly close the top with forceps, to give a virtually airtight seal, and reweigh it.

Note. As speed is essential after opening the ampoule, it is as well to place the cup in front of the balance, in readiness to receive the sample, and to move the rider and weights to their expected position before opening the ampoule.

\section{RESULTS}

\section{(a) Gain in weight on exposure}

Several experiments, in which small samples have been exposed in a cup on the balance pan, have shown that a saturation moisture content of $6-12 \%$ is usually reached within $2-4 \mathrm{hr}$. The rate of uptake appears to depend primarily on the sample weight. It is probably, therefore, a function of surface area, as might be expected.

For example, a $3 \mathrm{mg}$. sample picked up about $5 \%$ in $5 \mathrm{~min}$., and reached constant weight ( $13 \%$ increase) in $80 \mathrm{~min}$., whereas a $20 \mathrm{mg}$. sample picked up $0.6 \%$ in $5 \mathrm{~min}$., and had not reached constancy in $3 \mathrm{hr} .(9 \%$ increase), although exposure overnight gave a final increase of $12.5 \%$. Only in the case of the $3 \mathrm{mg}$. sample did we find an increase of $1 \%$ per min., as quoted by Flosdorf \& Webster (1937). The 
rate of gain in weight in every case was linear for at least $5 \mathrm{~min}$., and the moisture picked up was readily lost on drying at $50^{\circ} \mathrm{C}$. in a vacuum.

Sager (1952), describing similar experiments with large (1-5 g.) samples of dried plasma, concluded that the addition of glucose lowered the rate of uptake, and that a powdered sample was less hygroscopic than lumps. Unfortunately, however, he took widely varying sample weights, and his results could also be interpreted as showing a dependence on sample weight, rather than on the physical state of the sample.

\section{(b) Effect of variations in drying temperature}

Flosdorf \& Webster (1937) found, by carrying out determinations at different temperatures, that $50^{\circ} \mathrm{C}$. is the maximum temperature at which serum can be dried without decomposition, but gave no experimental details.

Porter \& Willits (1944), working with potato starch, Bennett \& Hudson (1954) with malt, and Messrs W. Edwards and Company (London) Ltd. (1954) with blood plasma, have determined the loss to constant weight at various temperatures, and have plotted the loss against the drying temperature. In each case the curve showed a break, indicating that at a certain temperature, dependent upon the sample, a partial decomposition occurs, with evolution of volatile matter. We have carried out similar experiments, the results of which are shown in Text-fig. 1. These results, unfortunately, are not convincing. but they indicate a slight increase in the loss of weight as the drying temperature is increased to about $75^{\circ} \mathrm{C}$, and a rather sharper increase above $75^{\circ} \mathrm{C}$. The losses in weight at $50^{\circ} \mathrm{C}$. are slightly higher than those at room temperature, but it was considered that the reduction in drying time obtained by working at $50^{\circ} \mathrm{C}$. outweighed this disadvantage.

\section{(c) Effect of variations in drying time}

Within the temperature range $40-80^{\circ} \mathrm{C}$., a virtually constant weight is attained in $45 \mathrm{~min}$., unchanged after at least $1 \mathrm{hr}$. further. For lower or higher temperatures, constant weight may only be attained after a longer time, indicating slow release of moisture at low temperatures, and slow decomposition at high temperatures. Typical curves of loss against time, at $50^{\circ} \mathrm{C}$, are shown in Text-fig. 2.

\section{(d) Effect of variation in vacuum}

No definite experiments have been made to determine the effect of variation in the vacuum applied during drying, but our experience with the method suggests that the vacuum, at least over the range $0.5-0.05 \mathrm{~mm}$. $\mathrm{Hg}$, has little or no influence on the results.

\section{(e) Reproducibility of the method}

A micro-balance will not usually give a reading better than $\pm 2-3 \mu \mathrm{g}$. under normal conditions (see, for example, Waber \& Sturdy, 1954). In view of the hygroscopic nature of the sample, and the time interval between the weighings, the recorded loss in weight cannot be expected to be accurate to better than about $10 \mu \mathrm{g}$., equivalent to $0.1 \%$ on a $10 \mathrm{mg}$. sample. Statistical analysis of the results 
of duplicate determinations on over 400 batches has shown that the standard deviation of the difference between duplicate values is equal to or better than $\pm 0 \cdot 14 \%$ for yellow-fever vaccine, and $\pm 0.25 \%$ for distemper vaccine.

\section{(f) Speed of the method}

The method has the great advantage of rapidity. One determination takes 45-60 min., but, using the twin desiccators shown, fifteen or more determinations can easily be carried out in a working day.

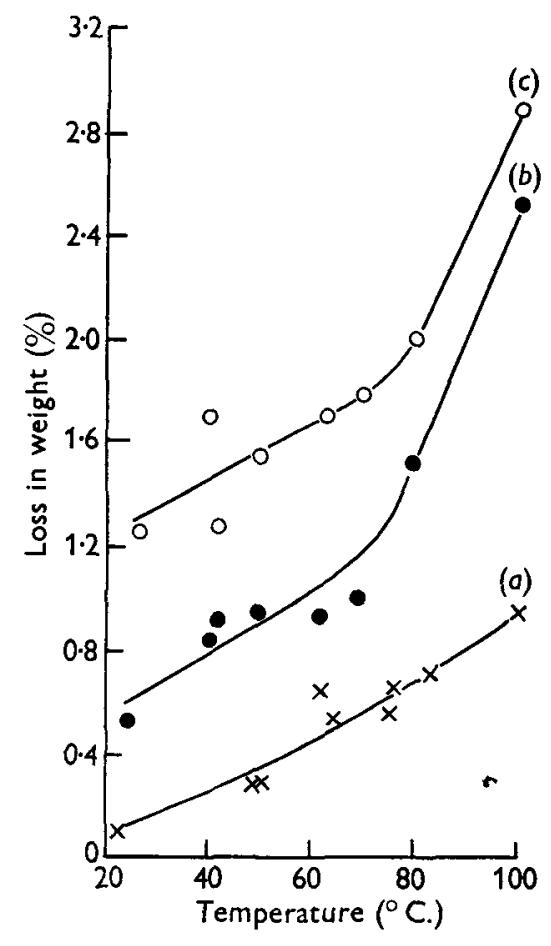

Fig. 1

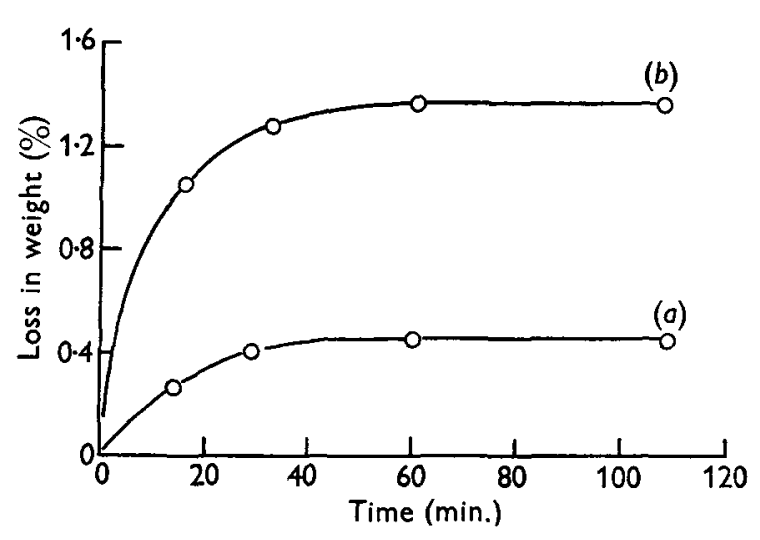

Fig. 2

Text-fig. 1. Effect of temperature of drying on loss in weight. Curve $(a)$ : yellow-fever vaccine. Curve $(b)$ : distemper vaccine; ampoules sealed immediately after freeze-drying. Curve (c) : distemper vaccine; ampoules sealed $1 \mathrm{hr}$. after removal from the freeze-drying desiccator.

Text-fig. 2. Effect of time of drying on loss in weight of distemper vaccine, dried at $50^{\circ} \mathrm{C}$. in vacuo. Curve $(a)$ : ampoule sealed immediately after freezendrying. Curve $(b)$ : ampoule sealed $1 \mathrm{hr}$. after removal from the freeze-drying desiccator.

\section{COMPARISON WITH OTHER METHODS}

(a) The American method

In order to try the standard American macro-method, a batch of rejected material was bulked, distributed into large ampoules in approximately $1 \mathrm{~g}$. amounts, and re-freeze-dried. On opening each ampoule, a small quantity was taken and analysed by the micro-method, and the remainder was transferred to a weighed flat-form weighing bottle, weighed, and dried over phosphorus pentoxide under vacuum at 
room temperature. Readings were taken after 24,70 and $96 \mathrm{hr}$., although approximately constant weight was apparently reached within $24 \mathrm{hr}$. In agreement with Sager (1952) it was found that a true constant weight was not obtained but that the loss in weight varied slightly from day to day, due probably to inherent errors in weighing a comparatively large glass vessel.

The material used was bulked and allowed to come to equilibrium with the atmosphere, over several weeks. Moisture determinations were again carried out by both methods. The results obtained are shown in Table 1 .

\section{Table 1. Moisture contents, determined by the micro-method and the standard American method}

$\begin{array}{lcc} & \begin{array}{c}\text { Micro-method } \\ (\%)\end{array} & \begin{array}{c}\text { Macro-method } \\ \text { Freeze-dried Sample 1 }\end{array} \\ \text { Freeze-dried Sample 2 } & 1 \cdot 40 & 0 \cdot 2 \\ \text { Freeze-dried Sample 3 } & 1.55 & 0.4 \\ \text { Hydrated Sample } & 1 \cdot 40 & 0 \cdot 2 \\ & \{6.55 & 6.97 \\ 6.30 & 6.88\end{array}$

\section{(b) The 'micro' Karl Fischer method}

A few samples of the distemper vaccine have been analysed by a 'micro' Karl Fischer method. Each ampoule contains 30-50 mg. of sample and gives a loss in weight of about $1 \%$, equivalent to $0 \cdot 3-0.5 \mathrm{mg}$. of water. As some details of the method used are believed to be novel, a brief description of it will be given.

\section{Apparatus}

Burettes. Two $2 \mathrm{ml}$. burettes, totally enclosed, similar to that described by Wiberley (1951) were used, one for Fischer reagent and one for water-in-methanol reagent.

Titration vessel. This was an approximately cylindrical vessel, about 2 in. deep by $\frac{1}{2}$ in. diameter. A side arm, 1 in. long, of the same diameter as the neck of the sample ampoule, was let into the bottom at an angle of about $45^{\circ}$. This carried a polythene connexion, by means of which the ampoule could be attached. The top was covered with a rubber cap (vaccine bottle cap) pierced with two holes, one of which admitted the burette tip, and the other the double electrode.

Electrical circuit. The 'dead-stop end-point' circuit was used (Foulk \& Bawden, 1926). The double electrode consisted of two platinum wires insulated from each other, and sealed through the closed end of a narrow glass tube.

\section{Reagents}

Fischer reagent. Commercial reagent (5 $\mathrm{mg}$. water $/ \mathrm{ml}$.) was diluted with anhydrous methanol to a strength of about $1 \mathrm{mg} . / \mathrm{ml}$.

Water-in-methanol reagent. Standard water-in-methanol (2.4 mg. water $/ \mathrm{ml}$.) was diluted with an equal volume of anhydrous methanol.

Procedure. Clean the ampoule containing the sample and weigh it to the nearest 
$0 \cdot 1 \mathrm{mg}$. on an analytical balance. Open the neck of the ampoule about $0.5 \mathrm{in}$. above the shoulder, and quickly run in an excess (1.5-2 ml.) of Fischer reagent. Swirl and attach the ampoule to the side arm of the titration vessel by means of the polythene connexion. Tilt so that all the liquid runs into the titration vessel, insert the tip of the water-in-methanol burette through the cap, and back titrate until the galvanometer returns to zero. Clean and dry the ampoule, including the piece broken from the neck, and re-weigh, to obtain the sample weight.

Standardize the reagents by means of the standard water-in-methanol solution. Some results obtained by this method are given in Table 2 .

Table 2. Moisture contents, determined by the micro-method and the Karl Fischer method

$\begin{array}{lcc} & \begin{array}{c}\text { Micro-method } \\ (\%)\end{array} & \begin{array}{c}\text { Karl Fischer method } \\ (\%)\end{array} \\ \text { Sample 1 } & 1 \cdot 15,1 \cdot 25,0 \cdot 90 & \mathbf{1} \cdot 0,1 \cdot 25,1 \cdot 35,1 \cdot 05 \\ \text { Sample 2 } & 0 \cdot 70,0 \cdot 90 & 1 \cdot 2,0 \cdot 70,0 \cdot 75,1 \cdot 10,0 \cdot 70\end{array}$

Control determinations, using empty ampoules which had been freeze-dried and sealed as usual, gave moisture contents of zero.

By this technique it was found difficult to get stable or constant end-points. The apparatus and technique were capable of refinement, but as the method was not applicable to all our samples, it was not further investigated.

(c) The vapour-pressure method

Through the courtesy of Messrs Edwards and Company (London) Ltd., some of our samples have been analysed by the vapour-pressure method, both at room temperature and at $50^{\circ} \mathrm{C}$. The results are shown in Table 3 .

Table 3. Moisture contents, determined by the micro-method and the vapour-pressure method

\begin{tabular}{|c|c|c|c|}
\hline & 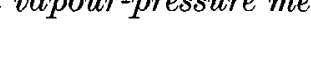 & Vapour-pres & e method $(\%$ \\
\hline & $\begin{array}{c}\text { Micro-method } \\
(\%)\end{array}$ & $\begin{array}{c}\text { At room } \\
\text { temperature }\end{array}$ & At $50^{\circ} \mathrm{C}$. \\
\hline Yellow-fever vaccine & $0 \cdot 19,0 \cdot 18,0 \cdot 25,0 \cdot 25$ & $0 \cdot 26$ & $0 \cdot 21$ \\
\hline Distemper vaccine & $0.46,0.45$ & - & 0.41 \\
\hline Distemper vaccine & $1 \cdot 37,1 \cdot 39,1 \cdot 26$ & - & $0.90,0.84$ \\
\hline
\end{tabular}

\section{DISCUSSION}

The biggest discrepancy in the comparative results given above is between the micro-method and the so-called American standard method, for samples of low moisture content. No convincing explanation can be offered for this difference, but the results provide a reason for our findings of 2-3\% loss for American samples alleged to contain less than $0.5 \%$ moisture, in agreement with Beckett (1951, and personal communication), who has found 4\% moisture in American samples, using 
the vapour-pressure method. Any attempted explanation of the results is complicated by the results on the hydrated material, for which the micro-method gives somewhat lower results.

The Karl Fischer method gives results in good agreement, but no account has been taken of the possibility of side reactions, and the agreement may be largely fortuitous.

The vapour-pressure method gives results in good agreement, although there appears to be a tendency for the results to be slightly lower by this method.

It can therefore be stated that the proposed micro-method gives results that are in agreement with, or are higher than, those given by other available methods. Since the moisture content is normally required to be less than a certain value, the possibility that the results may be high provides an additional safeguard, and is not therefore a very serious defect.

It is not inappropriate to point out that there is considerable controversy as to the meaning of the figures obtained for moisture content, i.e. whether they represent true residual moisture or 'water of constitution'. There is also no agreement as to whether there is an optimum moisture content for maximum stability, although several workers have shown a broad correlation between stability and moisture content (see, for example, Flosdorf, 1949; Hilleman, Buescher \& Smadel, 1951 ; and Hutton et al. 1951). The American National Institutes of Health require a moisture content of not more than $1 \%$ for certain freeze-dried vaccines, but there appears to be no convincing published work to show that this is a critical level or that it is the same for all types of organism.

These and other points have been mentioned recently in a review by Beckett (1954) and a fuller discussion is beyond the scope of the present paper.

\section{SUMMARY}

A micro-drying method is described, which is simple, rapid and reproducible. It has been shown to give results in reasonable agreement with the Karl Fischer method, and with the vapour-pressure method. The results on samples of low moisture content are, however, considerably higher than those by the so-called American standard method. The method has been in routine use for over 3 years.

The author's thanks are due to Mr A. Bennett, for carrying out much of the preliminary work on the method; to Dr D. G. ff. Edward, Mr W. A. Fitzgerald and Mr S. Pinfield, for helpful discussions, and the provision of special samples whenever necessary; to Dr Tudor S. G. Jones for assistance with the design and construction of the Karl Fischer apparatus; to Mr P. A. Young for the statistical analysis; to Messrs Edwards and Company (London) Ltd., for the determinations by the vapour-pressure method; and to his assistants, Miss M. Clarke, Mrs M. Richmond, Mr J. C. H. Stephens, and Mr J. Tanner for their help during the development of the method, and for carrying out several thousand routine analyses. 


\section{REFERENCES}

BecketT, L. G. (1951). In Freezing and Drying, R. J. C. Harris, ed., p. 160. London: The Institute of Biology.

BEскETT, L. G. (1954). In Biological Applications of Freezing and Drying, R. J. C. Harris, ed., p. 285. New York: Academic Press, Inc.

Bennett, A. \& Hudson, J. R. (1954). J. Inst. Brew. 60, 35.

Edwards, W. \& Co. (London) Ltd. (1954). Personal communication.

Fischer, K. (1935). Angeu. Chem. 48, 394.

Flosdorf, E. W. (1949). Freeze-Drying, New York: Reinhold Publishing Corp.

Flosdorf, E. W. \& Webster, G. W. (1937). J. biol. Chem. 121, 353.

Foulk, C. W. \& Bawden, A. T. (1926). J. Amer. chem. Soc. 48, 2045.

GardiNer, S. D. \& Farmiloe, F. J. (1954). Analyst, 79. 447.

Hilleman, M. R., Buescher, E. L. \& Smadex, J. E. (1951). U.S. Publ. Health Rep. 66, 1195. Hutton, R. S., Hilmoe, R. J. \& Roberts, J. L. (1951). J. Bact. 61, 309.

Levi, G. B., Murtaugh, J. J. \& Rosenblate, M. (1945). Industr. Engng Chem. (Anal. edn.), 17, 193.

MoComb, E. A. (1948). Anal. Chem. 20, 1219.

Makower, B. \& Myers, S. (1943). Proc. Inst. Food Tech. 156.

Porter, W. L. \& Willits, C. O. (1944). J. Assoc. off. agric. Chem. 27, 179.

Pregl, F. (1945). Quantitative Organic Micro-Analysis, 4th English ed., p. 19. London: J. and A. Churchill, Ltd.

Riddick, J. A., Toops, E. E., Wiemane, R. L. \& Cundiff, R. M. (1954). Anal. Chem. 26, 1149.

SAGER, H. (1952). Pharm. Acta Helvet. 27, 121.

Schroeder, C. W. \& Nair, J. H. (1948). Anal. Chem. 20, 452.

Sobel, H. (1953). Anal. Chem. 25, 1756.

Thomann, J. \& Kaelin, A. (1938). Pharm. Acta Helvet. 13, 23.

Vincent, R. S. \& Simons, A. (1940). Proc. phys. Soc. 52, 489.

Waber, J. T. \& Sturdy, G. E. (1954). Anal. Chem. 26, 1177.

Wibertey, J. S. (1951). Anal. Chem. 23, 656.

(MS. received for publication 17. v. 55) 